\title{
Delineate the role of plant fuorocoumarin derivatives on hepatocarcinoma, DNA Topoisomerase I and mitotic cell division
}

\author{
Ahmed Esmat ${ }^{1}$, Nahla A Farag ${ }^{2}$, Hoda Barakat ${ }^{3}$, Dina Salem ${ }^{3}$ and Noha S Khalifa ${ }^{3 *}$ \\ ${ }^{1}$ Department of pharmacology and Toxicology, Faculty of Pharmacy, Ain shams University, Abassia, Cairo, Egypt \\ ${ }^{2}$ Pharmaceutical Chemistry Department, Faculty of Pharmacy, Misr International University, Km 28 Cairo-Ismailia Road (Ahmed Orabi District) Cairo, Egypt \\ ${ }^{3}$ Unit of cell and Genetics, Botany Department, Faculty of Science, Ain Shams University, Abassia, Cairo, Egypt
}

\begin{abstract}
Furocoumarins are produced by plant members via the phenylpropanoid pathway. Natural and chemically synthesized furocoumarins exhibit promising anticancer activity. This work aims to increase our understanding of the mechanism by which these compounds can suppress cancer. Therefore, two medicinal plants, Apium graveolense \& Ruta graveolense and 10 synthesized furocoumarin derivative compounds were tested against hepatocellular carcinoma cell line (HepG-2). Our results indicated that compound 9 exhibited the highest cytotoxic activity $\left(\mathrm{IC}_{50}=11.9 \mu \mathrm{M}\right)$. Other compounds exerted less cytotoxic activity ranging from $\mathrm{IC}_{50}=28.38 \mu \mathrm{M}$ for compound one to $\mathrm{IC}_{50}=67.10 \mu \mathrm{M}$ in case of compound 5 . The natural crude extracts exhibited the lowest cytotoxic activity on HepG-2 with values of $\mathrm{IC}_{50}=312.4$ and $445.7 \mu \mathrm{M}$ for Ruta graveolens and Apium graveolens, respectively. Compound 9 was found to inhibit topoisomerase I enzyme, based on the molecular docking analysis, and significantly suppressed the mitotic cell division in the meristematic cells of pea (Pisum sativum) root tips.
\end{abstract}

\section{Introduction}

Cancer is one of the major deaths causing disease that accounts for 8.2 million deaths all over the world, with 745000 deaths resulted from liver cancer alone [1]. Natural and chemically synthesized furocoumarins exhibit promising anticancer activity [2]. Furocoumarins are produced by plant members of families Apiaceae, Umbelliferae, and Rutaceae [3]. They are synthesized in plants via the phenylpropanoid pathway [4]. Their chemical structure consists of a furan ring fused with coumarin either in a linear (psoralen) or angular (angelicin) manner. Furocoumarins and other phytochemicals can induce apoptosis in human promyelocytic leukemia, HL-60 cells [4], control cancer progression [5] and act as hepatoprotective agents [6]. Photosensitizer effect in combination with UVA irradiation $(320-380 \mathrm{~nm})$ is used particularly with linear furocoumarin psoralen derivatives in medicine for the treatment of many dermatological disorders including psoriasis $[7,8]$. During the phototoxic reaction, furocoumarins intercalate DNA to form a non-covalent psoralen-DNA complex. This property is useful in cancer therapy as it can prevent DNA replication [9]. On the other hand, the angular furocoumarin (angelicin) inhibits DNA synthesis and consequently blocks cell division by different mechanism as it could not form inter-strand cross-linkage with DNA due to its geometry. Angelicin (angular furobenzopyrone) has been proved to have lower genotoxicity than psoralens (linear furobenzopyrones) and lacks skin erythemogenic effect [10]. Furocoumarins are also able to activate the production of singlet oxygen which results in protein inactivation and can also interfere with the action of cytochrome $\mathrm{P} 450$, the target of many drugs [11]. The inhibition of topoisomerase enzyme by natural furocoumarin compound was previously recorded in many studies $[12,13]$. However, the spatial orientation, intricate ring systems and numerous chiral centers present in natural crude extracts are often retarding its mechanism of action as anticancer agents [14]. This made the synthesis of analogues with favorable features an important target in this respect. Topoisomerases are crucial for DNA replication and thus, considered major targets for many anticancer drugs. DNA Topoisomerase I (Topo I) relaxes supercoils generated during replication/transcription process [15]. It also mediates DNA relaxation by creating a transient singlestrand break in the DNA duplex. This transient nick allows the broken strand to rotate around its intact complement, effectively removing local supercoils. Strand nicking results from the transesterification of an active-site tyrosine (Tyr-723) at a DNA phosphodiester bond forming a 3_-phosphotyrosine covalent enzyme-DNA complex. After DNA relaxation, the covalent intermediate is reversed when the released 5_$\mathrm{OH}$ of the broken strand reattacks the phosphotyrosine intermediate in a second transesterification reaction. The rate of religation is normally much faster than the rate of cleavage, and this ensures that the steadystate concentration of the covalent 3-phosphotyrosyl topo I-DNA complex remains low [16]. There are two types of topoisomerase inhibitors: one stabilizes the topoisomerase-DNA complex $t$ then leads to apoptosis due to formation of chromosomal breaks, while the second type will antagonize topoisomerase and prevent DNA replication [17]. Camptothecin (CPT) is the only topo I inhibitor which is used

Correspondence to: Noha S Khalifa, Unit of cell and Genetics, Botany Department, Faculty of Science, Ain Shams University, Abassia, Cairo, Egypt, E-mail: nohakhalifa@hotmail.com

Key words: Furocoumarins; Ruta graveolens; Apium graveolens, hepatocarcinoma (Hep-G2); mitotic index; topoisomerase I; molecular docking

Received: October 11, 2017; Accepted: October 25, 2017; Published: October 31,2017 
in clinical trials. It exerts its inhibitory effect through stabilizing the enzyme-DNA complex [18]. CPT was used in this study as a positive control. Thus, our present study aimed first to compare the biological activity of natural and synthetic plant furocoumarin compounds on cancer cell viability. Secondly, the compound with the most potent activity was further tested for its effect on: 1-DNA Topo I enzyme activity using molecular docking technique; 2 : the mitotic index and chromosomal abnormalities on the root cell of pea plants.

\section{Materials and method}

\section{Chemical compounds}

The chemical formulae of synthetic compounds used in this study are shown in Table 1. They were synthesized according to [19]. Compound 10 is newly synthesized following the equation shown in Figure 1. The chemical structures of all synthesized compounds were confirmed using both analytical and spectrophotometrical tests. In addition, the crude plant extracts of Apium graveolense and Ruta graveolense were used as references for comparison as they contain high content of the plant linear coumarin "psoralen".

\section{Plant material}

Pisum sativum seeds var. master B were purchased as a true breeding line from the Agricultural Research Center, Ministry of Agriculture, Giza, Egypt. Apium graveolense and Ruta graveolense were collected as fresh samples from the certified farm of Sekem herb company. Cairo, Egypt.

\section{Plant extract}

Methanolic plant extracts were prepared immediately after collecting plant samples according to the method described by [20]. Briefly, $200 \mathrm{~g}$ fresh leaves were cleaned and dried in solar oven, grinded into powder and extracted with methanol at room temperature using steel percolator ( $450 \mathrm{ml}$ for each $75 \mathrm{~g}$ powder). The powder was soaked in methanol at room temperature overnight. Methanol extract was filtered sterilized then dried in rotvapour under vacuum of 120 millibar in a water bath at $40^{\circ} \mathrm{C}$. Finally, extracts were lyophilized using a freeze dryer to eliminate water traces and stored at $-20^{\circ} \mathrm{C}$ until being used.

\section{Cytological studies}

Chromosome structure and abnormalities were observed in roots of Pisum sativum seedling treated with compound 9 as the highest cytotoxic and compound 8 as a compound with average cytotoxic effect. In this study, 1-2 cm long intact roots of Pisum sativum seedlings germinated in distilled water were soaked in the test solutions for 4 and 24 hours. At the end of treatment time, roots were excised and placed in carnoy's fixative (absolute alcohol: glacial acetic acid 3:1) for 24 hours then washed and kept in $70 \%$ ethanol in the fridge until ready to use. Root tips were hydrolyzed in $1 \mathrm{~N} \mathrm{AR} \mathrm{HCl}$ at 58-60 oC for about 1112 minutes. Root tips were stained with leuco basic fuchsin according to [21]. The root tips were squashed in $45 \%$ acetic acid. Dehydration was done using ascending series of ethyl alcohols; $30 \%, 50 \%, 70 \%, 95 \%$, absolute alcohol; then absolute alcohol: xylene (1:1) and finally pure xylene; keeping root tips 5 minutes in each concentration. Preparation was then mounted in Canada balsam and placed in an oven at $30^{\circ} \mathrm{C}$ for 2-3 days until dry. The preparations were examined microscopically with the power of 400x. For each concentration, 90 fields were examined. The results were statistically analyzed using t-test. All treatments were in triplicate.
Table 1. Synthetic fuorocoumrine derivatives used in this study

\begin{tabular}{|c|c|c|}
\hline Name & Chemical formula & No. \\
\hline $\begin{array}{l}\text { 4-methyl-8-toloyl-9-phenyl- } \\
\text { 2H-furo[2,3-h]chromen-2-one. } \\
\text { benzopyran-2-one. }\end{array}$ & & 1 \\
\hline $\begin{array}{l}\text { 4-methyl-8-anisoyl-9-tolyl-2H- } \\
\text { furo[2,3-h]chromen-2-one }\end{array}$ & & 2 \\
\hline $\begin{array}{l}\text { 4-Phenyl-8-p-anisoyl-9-phenyl-2H- } \\
\text { furo[2,3-h]chromen-2-one }\end{array}$ & & 3 \\
\hline $\begin{array}{l}\text { 4-Phenyl-8-p-anisoyl-9-p-anisyl-2H- } \\
\text { furo[2,3-h]chromen-2-one. }\end{array}$ & & 4 \\
\hline $\begin{array}{l}\text { 5-Phenyl-3-tolyl-7H-furo[3,2-g] } \\
\text { chromen-7-one }\end{array}$ & & 5 \\
\hline $\begin{array}{l}\text { 8-Benzoyl-9-methyl-4-phenyl-2H- } \\
\text { furo[2,3-h]chromen-2-one }\end{array}$ & & 6 \\
\hline $\begin{array}{l}\text { 8- Anisoyl-9-methyl-4-phenyl-2H- } \\
\text { furo[2,3-h]chromen-2-one }\end{array}$ & & 7 \\
\hline $\begin{array}{l}\text { 8-p-Bromophenyl-9-methyl-4-phenyl- } \\
\text { 2H-furo[2,3-h]chromen-2-one }\end{array}$ & & 8 \\
\hline $\begin{array}{l}\text { 4,9-dimethoxy-5-methyl-7-oxo-7H- } \\
\text { furo[3,2-g]chromene-6-carbonitrile }\end{array}$ & " & 9 \\
\hline $\begin{array}{l}\text { 4,9-dimethoxy-5-methyl-6-(4-ethyl- } \\
\text { 5-mercapto-4H-1,2,4-triazol-3-yl)-7- } \\
\text { oxo-7H-furo[3,2-g]chromene }\end{array}$ & 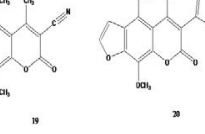 & 10 \\
\hline
\end{tabular}

\section{Cell culture}

HepG-2 cells were purchased from Vacsera (Pharmaseutics, Cairo, Egypt). Entity of cells was confirmed using STR DNA profile assay for human cells authenticaton following the manufacturer instructions (Promega, WI,USA). HepG-2 cells were maintained during the time of the experiment in RPMI-1640 medium, supplemented with $10 \%$ heat inactivated FBS, penicillin $(50 \mathrm{U} / \mathrm{ml})$ and streptomycin $(50 \mathrm{mg} / \mathrm{ml})$ at $37^{\circ} \mathrm{C}$ in a humidified atmosphere containing $5 \% \mathrm{CO}_{2}$. The cells were subjected to serial sub-culturing in order to keep it as a homogenous monolayer. Equal cell number were sub cultured and treated with 


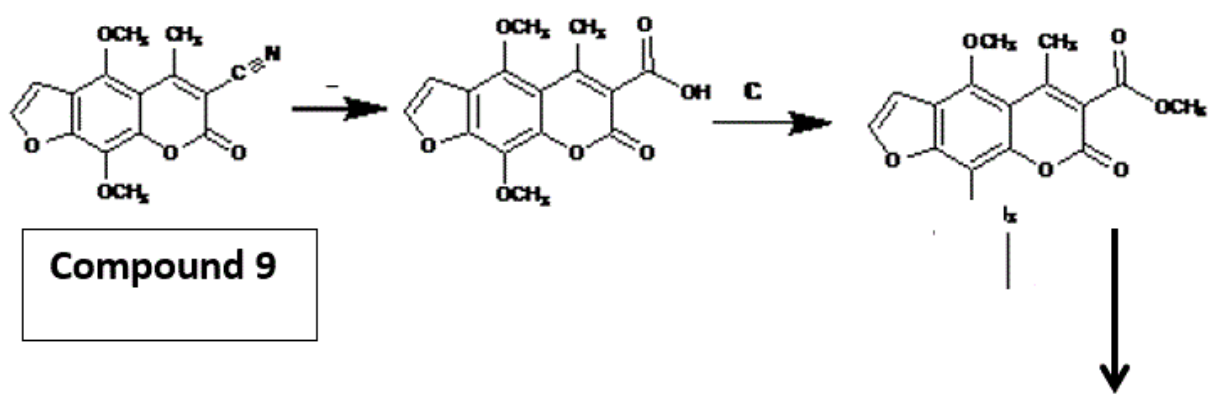

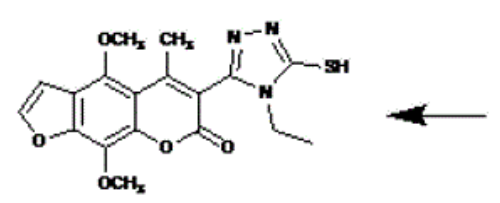

Compound 10

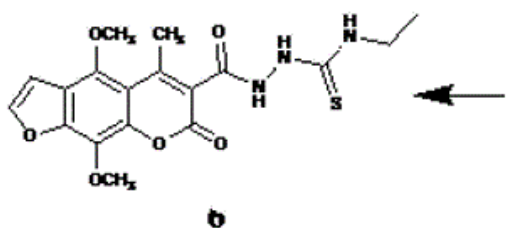

$\mathbf{b}$

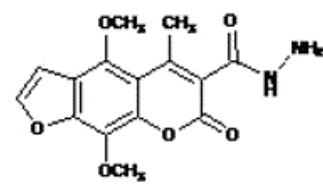

5

Figure 1. Mechanism of compound 10 formation from compound 9

$0.1,1,10,100$, and $1000 \mu \mathrm{M}$ of each compound each at a time. Each experiment was done in replicates of three and repeated twice to make sure that the results are reproducible. All chemicals used, except STR assay kit, were purchased from Sigma Aldrish (USA).

\section{SRB cytotoxicity assay}

Cytotoxicity was determined using the sulforhodamine B (SRB) method as described by [22]. Exponentially growing cells were collected using $0.25 \%$ Trypsin-EDTA and seeded in 96-well plates at 1000-2000 cells/well in RPMI-1640 supplemented medium. After $24 \mathrm{~h}$, cells were incubated for $72 \mathrm{~h}$ with various concentrations of the tested compounds. Following $72 \mathrm{~h}$ treatment, the cells were fixed with $10 \%$ trichloroacetic acid for $1 \mathrm{~h}$ at $4^{\circ} \mathrm{C}$. Wells were stained for $10 \mathrm{~min}$ at room temperature with $0.4 \%$ SRB dissolved in $1 \%$ acetic acid. The plates were air dried for $24 \mathrm{~h}$ and the dye was solubilized with Tris- $\mathrm{HCl}$ for 5 min on a shaker at $1600 \mathrm{rpm}$. The optical density (OD) of each well was measured spectrophotometrically at $564 \mathrm{~nm}$ using ELISA microplate reader (ChroMate4300, FL, USA). The $\mathrm{IC}_{50}$ values were calculated according to the equation of Boltzman sigmoidal concentrationresponse curve, using the nonlinear regression fitting models using version 5 of GraphPad software (GraphPad Software, Inc., CA, USA).

\section{Molecular modelling studies}

The discovery studio software version 2.5 computer docking program was used in this study. This program is well known to predict favorable protein-ligand complex structures with reasonable accuracy and speed [23]. The most promising compound number 9 and camptothecin (CPT) as a positive control (Figure 2) were placed, each at a time, into the binding site of the target macromolecule in a non-covalent fashion as described before $[13,24]$. Automated docking studies were carried out using the scoring functions and hydrogen bonds formed with the surrounding amino acids to predict binding modes, binding affinities and orientation of these compounds at the active site of the topoisomerase I. Prior to the docking, optimization was done by redocking of the positive control bound in the topo-I active site to validate the docking protocol. The generated most stable conformer was virtually used for afterward docking with compound 9. The final docked models were energetically minimized and used to

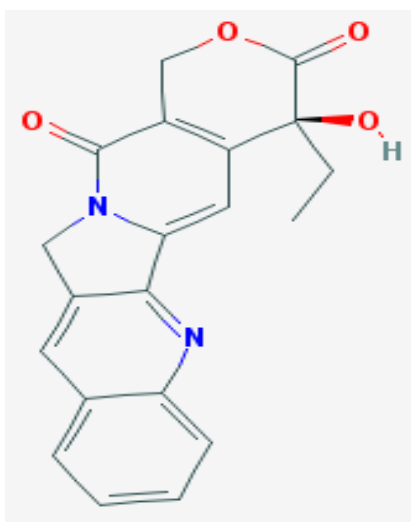

Figure 2. The chemical formula of camptothecin. (CPT) TopoI inhibotor which used in this study as a positive control

predict the interaction of compound 9 as a ligand with the amino acids in the active site of the enzyme.

\section{Docking study}

The general scheme for docking mechanism used in this study is illustrated in Figure 3. Molecular docking in this study was based on the $\mathrm{x}$ ray generated crystal structures of topoisomerase I which was obtained from the protein data bank in PDB formate (http://www.rcsb. org/pdb/welcome.do) (PDB ID: 1sc7 human topoisomerase I (TopoI) [25]. Protein was prepared using prepare protein parameter which cleans up common problems in the input protein structure for further processing. For instance, the program inserts missing atoms in residues as hydrogen to remove alternate conformations. All waters and free ions were removed as well. Camptothecin and furocoumarin analogues were prepared from ligands prepare tool which adds hydrogen, fix bad valencies and generates a 3D coordinates using catalyst. Docking was performed using (CDOCKER) protocol. Pose cluster radius was set to $0.5 \AA$, top hits were set to 10 and other docking parameters were kept at default.

Molecular docking (MD) data were analyzed using Accelrys Discovery studio 2.5 software using the Dock ligands (CDOCKER) 


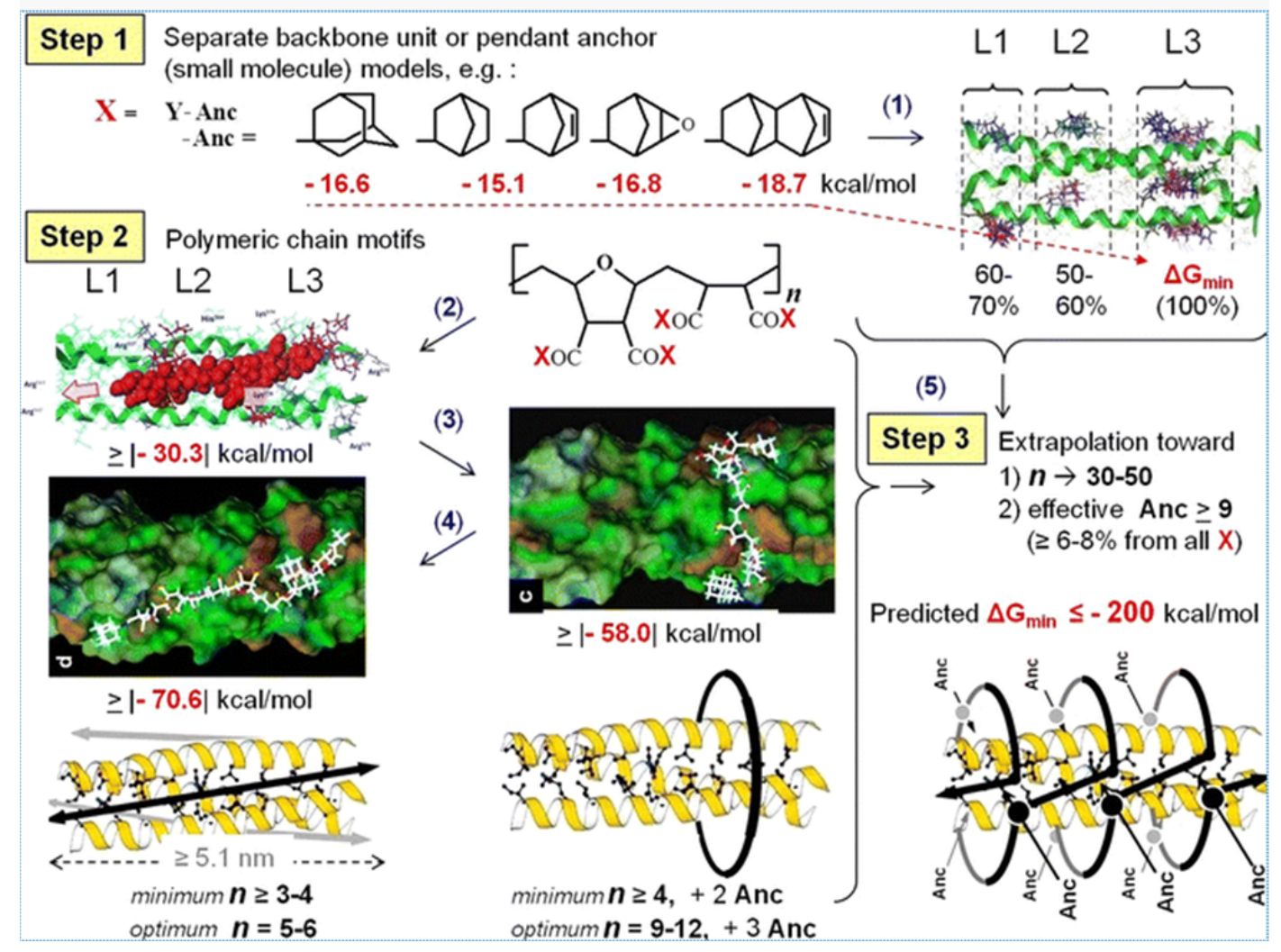

Figure 3. General scheme of the docking based modeling interaction using molecular docking program

protocol. Random ligand conformations were generated using high temperature MD in order to run a refinement docking of any number of ligands against a single protein receptor. The amino acids of the binding site where defined using data in pdbsum (http:// www.ebi.ac.uk/thoronton-srv/databases/pdbsum). Various scoring functions were applied to the ligands including CDOCKER_ENERGY (CHARMm energy: interaction energy plus ligand strain) andCDOCKER_INTERACTION_ENERGY: interaction energy only). Poses are sorted by CHARMm energy and the top scoring poses were calculated according to CDOCKER_ENERGY [26].

\section{Results and discussion}

The antiproliferative activity of furocoumarin compound derivatives against liver cancer cell lines was reported in many studies [27]. Despite of their moderate toxic effect on HepG-2 cells, they are less toxic on normal cells if compared with other anticancer drugs such as 5-Fluorouracil (5-FU) and Doxorubicin (DOX). Here, we tested the cytotoxic effect of newly synthesized furocoumarin analogues and the crude extracts of Apium graveolense and Ruta gravelense on hepatocellular carcinoma by treating HepG-2 cell line with different concentrations of these compounds for 72 hours using SRB cytotoxicity assay as shown in Table 2 . It is worth to mention that the mechanism of cancer inhibition through the phototoxic reactions of furocoumarins is excluded in this study as all treatments were done in the dark. The results indicated that proliferation in treated cells was reduced in a dose dependent manner. However, the cytotoxic effect was more observed at higher concentrations of 100 and $1000 \mu \mathrm{M}$ in all treatments in all compounds used as shown in Table 2. The highest reduction in viability \% was observed in cells treated for $72 \mathrm{~h}$ at the concentration of $1000 \mu \mathrm{M}$ with compound one $(0.9 \pm 1.1)$, compound
$7(1 \pm 0.2)$ and compound $9(1.5 \pm 0.7)$ as compared to positive control $\operatorname{DOX}(0.8 \pm 0.2)$ (Table 2). Compound 9 exhibited the highest $\mathrm{IC}_{50}=11.9$ $\mu \mathrm{M}$. Other compounds had relatively low $\mathrm{IC}_{50}$ ranging from $22.8 \mu \mathrm{M}$ (compound 10) to $67.10 \mu \mathrm{M}$ (compound 5) as shown in Table 3. One of the recent studies used a compound called 8-MOP with similar chemical structure composition to our compounds. It was reported that 8-MOP can inhibit cancer by inducing apoptosis in HepG-2 either in light or dark conditions by increasing ROS generation and inhibiting ERK1/2 pathway [28]. In another study, imperatorin (a furocoumarin isolated from Urena lobata L. (Malvaceae) was found to inhibit cell growth in SNU 449 (liver cancer) and HCT-15 (colon cancer) in a dose dependent manner. Imperatorin was found to down regulate the expression of the anti-apoptotic protein Bcal-2 and upregulate the expression of the proapoptotic protein Bax. Thus, the anticancer activity of imperatorin was mainly due to directing cancer cells towards apoptosis pathway as well [29]. In addition, natural furocoumarins like Bergamottin, extracted from grapefruit, can induce chemosensitization and apoptosis through the inhibition of STAT3 signaling pathway in tumor cells. STAT3 gene is responsible for the regulation of cell cycle and apoptosis [30]. Recently, it was suggested that furocoumarins exert their anticancer activity through the inhibition of topoisomerase enzyme [12]. Topoisomerases (Topo I \& II) are enzymes that control the DNA relaxation/coiling during replication and transcription processes of DNA in living cells [31]. Topo I enzyme initiates the cleavage of DNA molecule at a single strand while Topo II cleaves both strands. The accumulation of cleaved fragments will result into the cell death either by forcing the cell into apoptosis or by arresting cell cycle [32]. To date, the exact mechanism by which Topo I targeting drugs achieve their selective toxicity is not fully understood. Interestingly, Topo I inhibitor drugs depend on the length of exposure rather 
Table 2. Viability percentage of HepG-2 liver cell carcinoma treated for 72 hours with furocoumarin compounds (1-10) and 2 natural crude extracts (Apium graveolense and Ruta graveolense). Each value is a mean of 3 replicates

\begin{tabular}{|c|c|c|c|c|c|c|c|c|c|c|c|c|c|}
\hline \multirow[t]{2}{*}{$\begin{array}{c}\text { Concentration } \\
\mu \mathrm{M}\end{array}$} & \multicolumn{13}{|c|}{$\begin{array}{c}\% \text { of viability (Mean } \pm \text { SD) } \\
\text { Compound No. }\end{array}$} \\
\hline & 1 & 2 & 3 & 4 & 5 & 6 & 7 & 8 & 9 & 10 & $\begin{array}{l}\text { Apium } \\
\text { graveolens }\end{array}$ & $\begin{array}{c}\text { Ruta } \\
\text { graveolens }\end{array}$ & Doxorubsin \\
\hline 0.1 & $97.5 \pm 6.7$ & $91.9 \pm 3.3$ & $100.6 \pm 2.5$ & $101.4 \pm 0.8$ & $105.1 \pm 1.8$ & $106.0 \pm 2.5$ & $96.1 \pm 3.5$ & $101.8 \pm 2.1$ & $95.0 \pm 3.5$ & $85.5 \pm 4.4$ & $85.4 \pm 11.6$ & $95.5 \pm 5.5$ & $76.8 \pm 51$ \\
\hline 1 & $97.1 \pm 3.1$ & $85.5 \pm 3.8$ & $98.7 \pm 6.7$ & $101.4 \pm 2.6$ & $105.7 \pm 3.2$ & $98.7 \pm 6.7$ & $95.1 \pm 3.5$ & $104.5 \pm 2.5$ & $99.0 \pm 3.0$ & $65.9 \pm 4.8$ & $87.6 \pm 8.5$ & $102.3 \pm 4.2$ & $41.2 \pm 6.9$ \\
\hline 10 & $70.0 \pm 4.3$ & $73.8 \pm 10.1$ & $77.0 \pm 6.0$ & $75.5 \pm 3.3$ & $88.0 \pm 4.4$ & $81.3 \pm 10.2$ & $86.7 \pm 4.3$ & $94.5 \pm 5.0$ & $53.5 \pm 5.3$ & $59.1 \pm 3.9$ & $89.3 \pm 0.6$ & $94.7 \pm 2.4$ & $23.8 \pm 1.7$ \\
\hline 100 & $24.6 \pm 2.9$ & $35.4 \pm 7.0$ & $34.3 \pm 11.2$ & $39.9 \pm 5.9$ & $47.5 \pm 3.8$ & $37.2 \pm 6.7$ & $32.1 \pm 6.0$ & $45.7 \pm 5.3$ & $4.6 \pm 0.7$ & $28.6 \pm 1.4$ & $65.6 \pm 1.8$ & $68.6 \pm 5.9$ & $12 \pm 1.9$ \\
\hline 1000 & $0.9 \pm 1.1$ & $19.5 \pm 1.3$ & $5.3 \pm 1.8$ & $4.1 \pm 2.1$ & $11.4 \pm 2.1$ & $6.7 \pm 0.8$ & $1 \pm 0.2$ & $15.7 \pm 2.2$ & $1.5 \pm 0.7$ & $15.5 \pm 2.8$ & $5.0 \pm 4.2$ & $3.6 \pm 1.2$ & $0.80 \pm 0.2$ \\
\hline
\end{tabular}

Table 3. In vitro cytotoxic activity of synthetic and natural furocoumarin compounds tested against HepG-2 cell line represented by Ic s0 $_{50}$ values

\begin{tabular}{|c|c|c|c|c|c|c|c|c|c|c|c|c|}
\hline Compound & $\mathbf{1}$ & $\mathbf{2}$ & $\mathbf{3}$ & $\mathbf{4}$ & $\mathbf{5}$ & $\mathbf{6}$ & $\mathbf{7}$ & $\mathbf{8}$ & $\mathbf{9}$ & $\mathbf{1 0}$ & $\begin{array}{c}\text { Apium } \\
\text { graveolens }\end{array}$ & graveolens \\
\hline $\begin{array}{c}\mathrm{Ic}_{50} \\
\mathrm{in} \mu \mathrm{M}\end{array}$ & 28.38 & 33.71 & 41.24 & 50.85 & 67.10 & 50.96 & 62.21 & 65.37 & 11.97 & 22.8 & 445.7 & 312.4 \\
\hline
\end{tabular}

than the concentration applied [33]. To determine if the anticancer activity detected in the furocoumarin derivative 9 is resulted from the inhibition of DNA replication via the interaction with Topo I enzyme, we compared the putative geometry of a protein-ligand complex of CPT-Topo I and Compound 9-TopoI using molecular docking binding model technique. Camptothecin (CPT) is a cytotoxic alkaloid isolated from Camptotheca acuminata tree and is used as anticancer drug. CPT inhibits cancer by binding with Topo I and consequently stops DNA replication. Molecular modelling had been proven to be successful and its results were parallel to those determined by $\mathrm{x}$ ray crystallography in many other studies [34]. We found that the binding model into the active site of Topo I (PDB ID: 1sc7) in compound 9 was in consistency with the proposed design and rational as described with that of CPT. To determine if compound 9 can be used as a potential Topo I drug inhibitor, we determined the system energetics in order to determine the affinity between the ligand (compound 9) and the target (Topo I) using the grid-based molecular dynamics docking algorithm, CDOCKER (CHARMm-based DOCKER). CDOCKER offers full information about ligand flexibility including bonds, angles....etc. The CDOCKER energy scores indicated favorable binding modes of camptothecin and compound 9 into the active site of Topo I (PDB ID: $1 \mathrm{sc} 7$ ) as shown Figures 4 and 5, respectively. It was found that the CDOCKER energy score of the original ligand camptothecin was4.38 forming five hydrogen bond interactions, 2 hydrogen bonds with Arg 364, one hydrogen bond with Lys 374, and two hydrogen bonds with Lys 425 as shown in Figure 4. On the other hand, CDOCKER energy score was-15.137 for compound 9-Topo I indicating its higher binding affinity and stronger bond with Topo I when compared with the positive control (CPT). Compound 9 binds with 2 hydrogen bonds where $\mathrm{O}$ of 2 Carbonyl form hydrogen bond with Lysine 425 with bond length $=2.09^{\circ} \mathrm{A}$, and another hydrogen bond between $\mathrm{N}$ of 3 Cyano and Tyrosine 246 forming a bond of $1.93^{\circ} \mathrm{A}$ as shown in Figure 5. From these results, it was found that both compounds bind topo I with Lys 425 Figures 4 and 5. It also showed that compound 9 has higher affinity and may act as dual inhibitor for topoisomerase I which in turn would likely lead to cancer inhibition through production of many DNA fragments which will force the cell to enter apoptotic events. This is likely can explain its effect as antiproliferative when used with HepG2 cells. Our results were in agreement with those obtained by [12], who found that furocoumarin compounds present in Ruta graveolens (psoralen, bergapten and xanthotoxin) showed Potent topoisomerase I inhibitory activity.

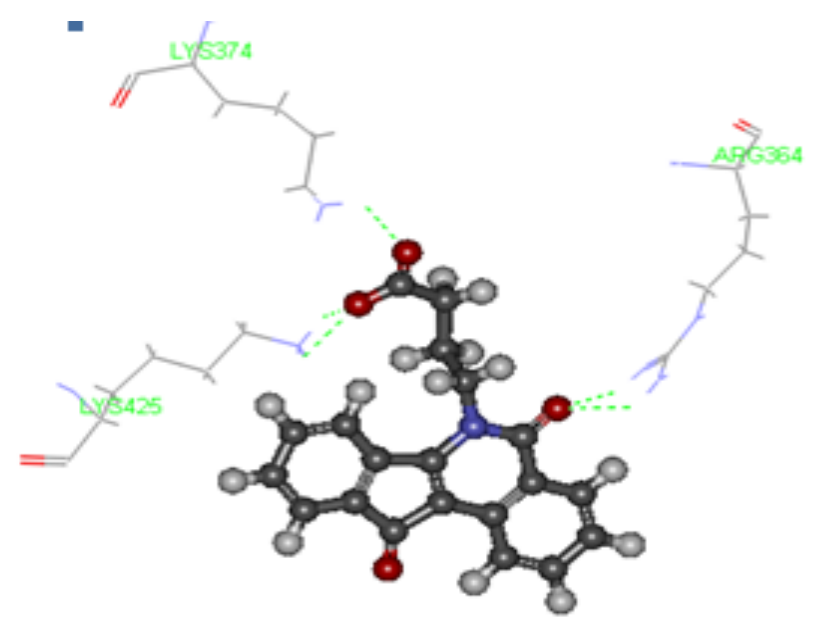

Figure 4. Binding mode of Camptothecin in the binding site of Topoisomerase I

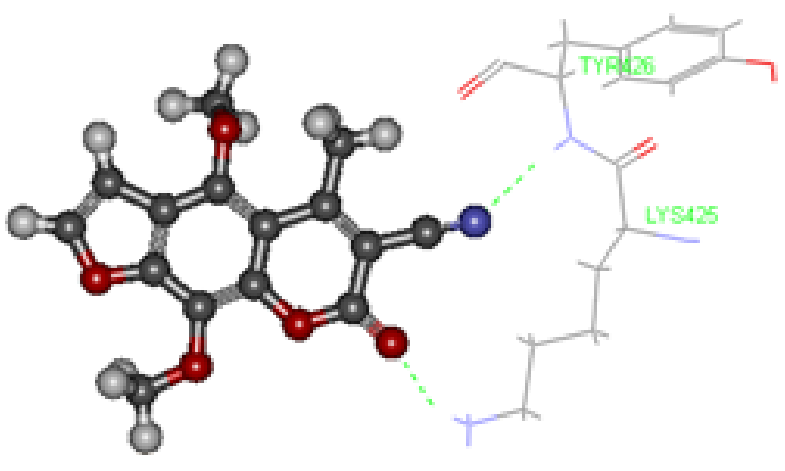

Figure 5. Binding mode of compound 9 in the binding site of Topoisomerase I

The induction of chromosomal aberration by furocoumarins was investigated by many scientists before using mammalian models [35]. Here, we further investigated the effect of compound 9 on the mitotic rate and chromosomal abnormalities using root cells of Pisum sativum (pea). This screening method had been proven to give accurate results in this respect [36]. The mitotic index (MI) decreased by increasing the treatment concentration being significant at $500 \mathrm{ppm}$ and highly significant at $1000 \mathrm{ppm}$ after 24 hours as compared to the control (Table 4) . No effect was detected in MI in root cells treated with compound 9 for 4 hours (Table 4). On the other hand, the overall 
Table 4. Frequency of normal cells at different mitotic phases after treating Pisum sativum root tips with the methanolic extract of compound 9 for 4 and 24 hours

\begin{tabular}{|c|c|c|c|c|c|c|c|c|c|c|}
\hline \multirow[t]{2}{*}{$\begin{array}{c}\text { Duration } \\
\text { (hours) }\end{array}$} & \multirow[t]{2}{*}{ Conc.(ppm) } & \multirow[t]{2}{*}{ Total Cells } & \multirow[t]{2}{*}{ Total Mitosis } & \multicolumn{2}{|c|}{ Prophase } & \multicolumn{2}{|c|}{ Metaphase } & \multicolumn{2}{|c|}{ Ana-Telophase } & \multirow{2}{*}{$\begin{array}{c}\text { MI } \\
\text { Mean } \pm \text { SE }\end{array}$} \\
\hline & & & & No. & $\%$ & No. & $\%$ & No. & $\%$ & \\
\hline \multirow{7}{*}{4 Hours } & Control & 4144 & 146 & 68 & 46.58 & 42 & 28.77 & 36 & 24.66 & $3.52 \pm 0.36316$ \\
\hline & Water +DMSO & 4234 & 148 & 69 & 46.62 & 43 & 29.05 & 36 & 24.32 & $3.50 \pm 0.650$ \\
\hline & 50 & 4126 & 144 & 67 & 46.53 & 44 & 30.56 & 33 & 22.92 & $3.49 \pm 0.41$ \\
\hline & 125 & 4364 & 150 & 66 & 44 & 46 & 30.6 & 38 & 25.33 & $3.42 \pm 0.34078$ \\
\hline & 250 & 4569 & 140 & 60 & 42.86 & 44 & 31.43 & 36 & 25.71 & $3.06 \pm 0.3853$ \\
\hline & 500 & 3450 & 94 & 37 & 39.36 & 32 & 34.04 & 25 & 26.6 & $2.7 \pm 0.36573$ \\
\hline & 1000 & 4490 & 102 & 36 & 35.29 & 38 & 37.25 & 28 & 27.45 & $2.27 \pm 0.37889$ \\
\hline \multirow{7}{*}{24 Hours } & Control & 3978 & 250 & 124 & 49.6 & 55 & 22 & 71 & 28.4 & $6.28 \pm 0.66$ \\
\hline & Water +DMSO & 4136 & 255 & 127 & 49.8 & 58 & 22.75 & 70 & 27.45 & $6.16 \pm 0.768$ \\
\hline & 50 & 4372 & 240 & 119 & 49.5 & 60 & 25 & 61 & 25.42 & $5.44 \pm 0.548$ \\
\hline & 125 & 4220 & 208 & 95 & 45.67 & 60 & 28.85 & 53 & 25.48 & $4.9 \pm 0.65754$ \\
\hline & 250 & 4350 & 154 & 64 & 41.56 & 55 & 35.71 & 35 & 22.72 & $3.54 \pm 0.5714$ \\
\hline & 500 & 4800 & 161 & 57 & 35.4 & 61 & 37.89 & 43 & 26.7 & $3.35 \pm 0.50435^{*}$ \\
\hline & 1000 & 4668 & 142 & 43 & 30.28 & 60 & 43 & 39 & 27.46 & $3.04 \pm 0.62 * *$ \\
\hline
\end{tabular}

Table 5. Frequency of abnormal cells at different mitotic phases after treating Pisum sativum root tips with the methanolic extract of compound 9 for 4 and 24 hours

\begin{tabular}{|c|c|c|c|c|c|c|c|c|c|c|c|c|c|c|c|}
\hline \multirow{2}{*}{ 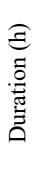 } & \multirow[b]{2}{*}{$\dot{\tilde{J}}$} & \multirow[b]{2}{*}{ 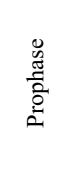 } & \multicolumn{6}{|c|}{ Metaphase } & \multicolumn{6}{|c|}{ Ana-telophase } & \multirow[b]{2}{*}{$\begin{array}{c}\text { Mean } \% \text { of } \\
\text { abnormal } \\
\text { cells }\end{array}$} \\
\hline & & & $\sum_{U}^{\prime \prime}$ & 岂 & 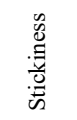 & 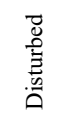 & 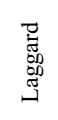 & 豞 & $\frac{8}{\overrightarrow{0}}$ & 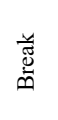 & 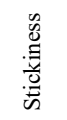 & 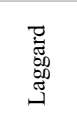 & 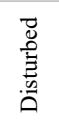 & 吾 & \\
\hline \multirow{7}{*}{+} & Cont. & & & & & 4.76 & & 4.76 & 2.78 & & & 2.78 & & 5.56 & $2.7 \pm 0.360$ \\
\hline & Water+DMSO & & & & & 4.65 & & 4.65 & 2.78 & & & 2.78 & & 5.56 & $2.7 \pm 0.54$ \\
\hline & 50 & & & & 4.55 & 4.55 & & 9.09 & 6.06 & & & 3.03 & & 9.09 & $4.86 \pm 1.29$ \\
\hline & 125 & & 6.52 & 2.17 & 4.35 & 2.17 & & 15.12 & 7.89 & & & 2.63 & & 10.53 & $7.33 \pm 2.18$ \\
\hline & 250 & & 9.09 & 2.27 & 6.81 & 4.55 & & 22.72 & 13.89 & & & 5.56 & & 19.44 & $12.14 \pm 2.54$ \\
\hline & 500 & 5.41 & 12.5 & 3.13 & 15.63 & 6.25 & 3.13 & 40.63 & 20 & 4 & & 12 & & 36 & $25.53 \pm 3.36^{* * *}$ \\
\hline & 1000 & 13.89 & 15.79 & 5.26 & 21.05 & 7.89 & 2.63 & 52.63 & 25 & 3.57 & & 14.29 & & 31.58 & $36.27 \pm 2.38^{* *}$ \\
\hline \multirow{7}{*}{$\stackrel{\sim}{\sim}$} & Cont. & -- & -- & -- & -- & 5.45 & -- & 5.45 & -- & -- & -- & -- & -- & -- & $1.20 \pm 0.49534$ \\
\hline & Water+DMSO & & & & & 3.45 & & 3.45 & 1.43 & & & & & 1.43 & $1.18 \pm 0.356$ \\
\hline & 50 & 2.52 & 3.33 & & 3.33 & 10 & & 16.67 & 8.2 & & & 3.28 & & 11.48 & $8.33 \pm 3.63$ \\
\hline & 125 & 8.42 & 10 & 1.67 & 8.33 & 10 & & 30 & 13.20 & 1.89 & 3.77 & 7.55 & & 26.42 & $19.23 \pm 2.64$ \\
\hline & 250 & 15.63 & 18.18 & 5.45 & 16.36 & 14.54 & 3.63 & 58.18 & 20 & 2.86 & & 11.43 & 5.71 & 40 & $36.36 \pm 4.97^{*}$ \\
\hline & 500 & 21.05 & 18.03 & 4.92 & 31.15 & 9.84 & & 63.93 & 23.26 & 4.65 & 6.98 & 11.63 & 2.33 & 48.84 & $44.72 \pm 1.85^{* * *}$ \\
\hline & 1000 & 23.26 & 20 & 5 & 35 & 11.6 & -- & 71.67 & 25.64 & 5.13 & 7.69 & 12.82 & & 51.28 & $51.4 \pm 4.259^{* *}$ \\
\hline
\end{tabular}
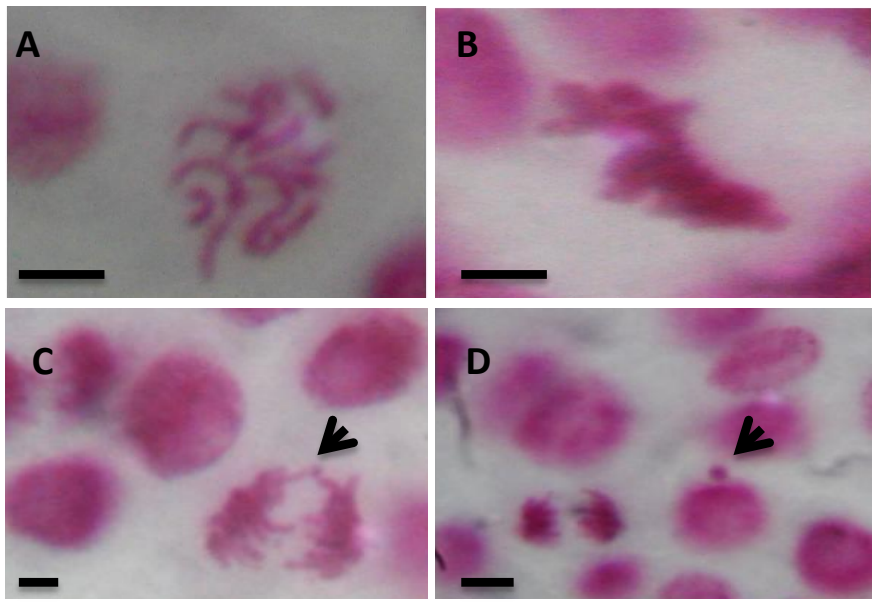

Figure 6. Representative micrographs showing some chromosomal abnormalities in the meristematic cells of the root tip of pea plants treated with different concentrations of compound 9. A: C-metaphase; B: Sticky metaphase; C: Chromosomal bridge at anaphase;

D: Micronucleus which results mainly from chromosomal breaks These abnormalities showed up mostly at concentrations 500 and 1000 ppm of compound 9 as shown in Table 5. Scale bars $=0.5 \mu \mathrm{m}$ percentage of chromosomal abnormalities showed proportional increase with dose and times of treatment with compound 9 as shown in Table 5. C-metaphase, stickiness, anaphase bridges and micronuclei were the most common chromosomal abnormalities found in HepG-2 cells treated with compound 9 (Figures 6A and 6B). C-metaphase appears due to complete inhibition of spindle fiber formation which results in the arrangement of chromosomes in the center of the cell as shown in Figure 6A. Stickiness is indicative of DNA intercalators (like furocoumarins) as shown in Figure 6B. Chromosomal breaks were also detected as a consequence for the presence of C-metaphase and Stickiness abnormalities. This result was in accordance with that of [37], where furocoumarins (psoralen and bergapten) presented in the methanolic extract of Brosimum gaudichaudii Trécul (Moraceae) resulted in chromosomal abnormalities in Chinese hamster ovary (CHO) cells. Chromosomal abnormalities within ana-telophase cells were lagging chromosomes, bridges, and chromosomal breaks Figure 6C. Chromosomal breaks results in the formation of micronuclei Figure 6D. These types of abnormalities were expected to appear as a result of chromosomal stickiness in metaphase cells. 


\section{Conclusion}

Our biological and molecular modeling results indicated that compound 9 is very promising as anticancer drug. Molecular docking indicated that the binding affinity and bond strength with TopoI enzyme were much higher in compound 9 than the positive control. Further studies need to be done to test this new compound on animal cells to decide upon its efficiency to treat cancer in animals and human systems.

\section{References}

1. Siegel R, Ma J, Zou Z, Jemal A (2014) Cancer statistics, 2014. CA Cancer J Clin 64: 9-29. [Crossref]

2. Hung WL, Suh JH, Wang Y (2017) Chemistry and health effects of furanocoumarins in grapefruit. J Food Drug Anal 25: 71-83.

3. Dugrand-Judek A, Olry A, Hehn A, Costantino G, Ollitrault P, et al. (2015) The Distribution of Coumarins and Furanocoumarins in Citrus Species Closely Matches Citrus Phylogeny and Reflects the Organization of Biosynthetic Pathways. PLOS ONE 10: e 0142757

4. Bourgaud F, Hehn A, Larbat R, Doerper S, Gontier E, et al. (2006) Biosynthesis of coumarins in plants: a major pathway still to be unravelled for cytochrome $\mathrm{P} 450$ enzymes. Phytochem Rev 5: 293-308.

5. Singh R, Agarwal R (2003) Tumor Angiogenesis: A Potential Target In Cancer Control by Phytochemicals. Current Cancer Drug Targets 3: 205-217.

6. Oh H, Ko EK, Jun JY, Oh MH, Park SU, et al. (2002) Hepatoprotective and free radical scavenging activities of prenylflavonoids, coumarin, and stilbene from Morus alba. Planta medica 68: 932-934. [Crossref]

7. Bhatnagar A, Kanwar A, Parsad D, De D (2007) Psoralen and ultraviolet A and narrowband ultraviolet $\mathrm{B}$ in inducing stability in vitiligo, assessed by vitiligo disease activity score: an open prospective comparative study. J Eur Acad Dermatol Venereol 21: 13811385. [Crossref]

8. Serrano-Pérez JJ, González-Luque R, Merchán M, Serrano-Andrés L (2008) The family of furocoumarins: Looking for the best photosensitizer for phototherapy. $J$ Photochem Photobiol A Chem 199: 34-41.

9. Ranganath YS, Harinadha Babu V, Sandeep G, Parameshwar R (2011) Synthesis and evaluation of some novel furocoumarin derivatives for radical scavenging profile and cytotoxic studies. J Chem Pharm Res 3: 62-68,

10. Dall'Acqua F, Martelli $P$ (1991) Photosensitizing action of furocoumarins on membrane components and consequent intracellular events. J Photochem Photobiol B 8: 235-254

11. Liu J, Sridhar J, Foroozesh M (2013) Cytochrome P450 Family 1 Inhibitors and Structure-Activity Relationships. Molecules 18: 14470-14495.

12. Diwan R, Malpathak N (2009) Furanocoumarins: Novel topoisomerase I inhibitors from Ruta graveolens L.. Bioorg Med Chem 17: 7052-7055.

13. Pani B, Barbisin M, Russo E, Tamaro M, Baccichetti F, et al. (1994) DNA damage and topoisomerase II inhibition induced by a benzopsoralen derivative. Mutat Res 311 : 277-285. [Crossref]

14. Magedov IV, Kireev AS, Jenkins AR, Evdokimov NM, Lima DT, et al. (2012) Structural simplification of bioactive natural products with multicomponent synthesis. 4. 4H-pyrano-[2,3-b]naphthoquinones with anticancer activity. Bioorganic \& medicinal chemistry letters 22: 5195-5198. [Crossref]

15. Wang JC (1996) DNA topoisomerases. Annu Rev Biochem 65: 635-692. [Crossref]

16. Champoux JJ (2001) DNA topoisomerases: structure, function, and mechanism. Annu Rev Biochem 70: 369-413. [Crossref]

17. Yonezawa Y, Tsuzuki T, Eitsuka T, Miyazawa T, Hada T, et al. (2005) Inhibitory effect of conjugated eicosapentaenoic acid on human DNA topoisomerases I and II. Arch Biochem Biophys 435: 197-206. [Crossref]

18. Koshkina N, Waldrep J, Knight V (2003) Camptothecins and Lung Cancer: Improved Delivery Systems by Aerosol. Current Cancer Drug Targets 3: 251-264.

19. Farag NAH, El-Tayeb W (2010) Design, synthesis and docking studies of new furobenzopyranones and pyranobenzopyranones as photoreagent towards DNA and as antimicrobial agents. Eur J Med Chem 45: 317-325.

20. El-Menshawi B (2003) The use of Biotechnological methods for drug discovery from Egyptian plants. Acad Sci Res Technol Technical report, Phase 1: 1-366.
21. Darlington CD, La Cour LF (1946) Nucleic acid and the beginning of meiosis. Nature 157: 875. [Crossref]

22. P Skehan et al. New colorimetric cytotoxicity assay for anticancer-drug screening. Journal of the National Cancer Institute, 82: 1107-1112,.

23. P. Pratheeshkumar et al. Luteolin inhibits human prostate tumor growth by suppressing vascular endothelial growth factor receptor 2-mediated angiogenesis.. PloS one, 7, 12, p. e52279, Dec. 2012.

24. P. Perego, G. Capranico, R. Supino, and F. Zunino Topoisomerase I gene expression and cell sensitivity to camptothecin in human cell lines of different tumor types.. Anticancer drugs, 5, 6, :645-9, Dec. 1994.

25. L. Stewart, M. R. Redinbo, X. Qiu, W. G. Hol, and J. J. Champoux A model for the mechanism of human topoisomerase I.. Science (New York, N.Y.), 279, 5356, :1534 41, Mar. 1998.

26. B. L. Staker et al. Structures of three classes of anticancer agents bound to the human topoisomerase I-DNA covalent complex.. Journal of medicinal chemistry, 48, 7, :2336-45, Apr. 2005.

27. El-Nakkady SS, Roaiah HF, El-Serwy WS, Bassyouni F, and Soliman AM Chemical and biological studies of some naturally occurring furocoumarins.. World $\mathrm{J}$ of Pharmaceu Res, 4, 7, :1794-1818, 2015.

28. H. Yang, J. Xiong, W. Luo, J. Yang, and T. Xi 8-Methoxypsoralen Induces Intrinsic Apoptosis in HepG2 Cells: Involvement of Reactive Oxygen Species Generation and ERK1/2 Pathway Inhibition.. Cellular physiology and biochemistry?: international journal of experimental cellular physiology, biochemistry, and pharmacology, 37, 1 , :361-74, 2015.

29. A. Rahman, S. A. Siddiqui, R. Jakhar, and S. C. Kang Growth inhibition of various human cancer cell lines by imperatorin and limonin from poncirus trifoliata rafin. Seeds.. Anti-cancer agents in medicinal chemistry, 15, 2, :236-41, 2015.

30. V. Calò et al. STAT proteins: From normal control of cellular events to tumorigenesis. Journal of Cellular Physiology, 197, 2, :157-168, Nov. 2003.

31. A. Y. Chen and L. F. Liu DNA Topoisomerases: Essential Enzymes and Lethal Targets Annual Review of Pharmacology and Toxicology, 34, 1, :191-218, Apr. 1994.

32. E. J. Walsby, S. J. Coles, S. Knapper, and A. K. Burnett The topoisomerase II inhibitor voreloxin causes cell cycle arrest and apoptosis in myeloid leukemia cells and acts in synergy with cytarabine. Haematologica, 96, 3, :393-399, Mar. 2011.

33. C. J. Gerrits, M. J. de Jonge, J. H. Schellens, G. Stoter, and J. Verweij Topoisomerase I inhibitors: the relevance of prolonged exposure for present clinical development. British journal of cancer, 76, 7, :952-62, 1997.

34. G. Wu, D. H. Robertson, C. L. Brooks, and M. Vieth Detailed analysis of grid-based molecular docking: A case study of CDOCKER?A CHARMm-based MD docking algorithm. Journal of Computational Chemistry, 24, 13, :1549-1562, Oct. 2003.

35. I. Alves, N. G. Oliveira, A. Laires, A. S. Rodrigues, and J. Rueff Induction of micronuclei and chromosomal aberrations by the mycotoxin patulin in mammalian cells: role of ascorbic acid as a modulator of patulin clastogenicity.. Mutagenesis, 15, $3,: 229-34$, May 2000.

36. N. S. Khalifa, H. S. Barakat, S. Elhallouty, and D. Salem Do cancer cells in human and meristematic cells in plant exhibit similar responses toward plant extracts with cytotoxic activities?. Cytotechnology, 67, 1,:123-33, Jan. 2015.

37. E. A. Varanda, G. L. Pozetti, M. V. Lourenço, W. Vilegas, and M. S. G. Radd Genotoxicity of Brosimum gaudichaudii measured by the Salmonella/microsome assay and chromosomal aberrations in CHO cells. Journal of Ethnopharmacology, 81, 2, $: 257-264,2002$

Copyright: (C2017 Esmat A. This is an open-access article distributed under the terms of the Creative Commons Attribution License, which permits unrestricted use, distribution, and reproduction in any medium, provided the original author and source are credited. 